\title{
Challenges in diagnosing infective endocarditis in COVID-positive patients - indication for emergency cardiac surgery
}

\author{
(DDubravka Šušnjar ${ }^{*}$, \\ (D)Josip Varvodić', \\ (1)Verica Mikecin', \\ (DIrzal Hadžibegović ${ }^{1,2}$, \\ DSavica Gjorgjievska', \\ (DDaniel Unić1, \\ (iDDavor Barić1, \\ (DIgor Rudež ${ }^{1,2}$ \\ 'University Hospital Dubrava \\ Zagreb, Zagreb, Croatia \\ ${ }^{2}$ University of Zagreb School \\ of Medicine, Zagreb, Croatia
}

RECEIVED:

March 28, 2021

ACCEPTED:

April 2, 2021

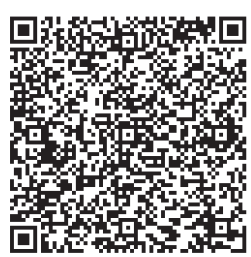

$\square$ Cardiologia Croatica 2021:16(5-6):180.
KEYWORDS: endocarditis, COVID-19 infection, surgery.

CITATION: Cardiol Croat. 2021;16(5-6):180-1. | https://doi.org/10.15836/ccar2021.180

*ADDRESS FOR CORRESPONDENCE: Dubravka Šušnjar, Klinička bolnica Dubrava, Avenija Gojka Šuška 6, HR-10000, Zagreb, Croatia. / Phone: +385-99-290-4019 / E-mail: dubravka.susnjar@gmail.com

ORCID: Dubravka Šušnjar, https://orcid.org/0000-0002-9644-9739 • Josip Varvodić, https://orcid.org/0000-0001-6602-699X Verica Mikecin, https://orcid.org/0000-0002-2362-4444 • Irzal Hadžibegović, https://orcid.org/0000-0002-3768-9134 Savica Gjorgjievska, https://orcid.org/0000-0002-4304-1852 • Daniel Unić, https://orcid.org/0000-0003-2740-4067 Davor Barić, https://orcid.org/0000-0001-5955-0275• Igor Rudež, https://orcid.org/0000-0002-7735-6721

|||||||||||||||||||||||||||||||||||||||||||||||||||||||||||||||||||||||||||||||||||||||||||||||||||||||||||||||||||||||||||

Introduction: Infective endocarditis (IE) is a life-threatening condition, especially when diagnosis is prolonged, as the symptoms of IE overlap with COVID-19 infection (Coronaviruses disease 2019) ${ }^{1-4}$ We present the case series of two patients with a diagnosis of IE concomitant with COVID-19 infection.

Case report: 36-year-old patient admitted to the hospital, due to pneumonia and meningitis caused by Streptococcus pneumoniae. Transthoracic echocardiography (TTE) showed paravalvular aortic abscess with mild aortic insufficiency without vegetations. Month after, patient had a positive COVID-19 swab, developed bilateral COVID-19 pneumonia, requiring oxygen therapy and respiratory support, and transferred in University Hospital Dubrava. Transesophageal echocardiography showed aortic root abscess with pseudoaneurysm in the projection of non-coronary cusp (NCC), destroyed NCC and left coronary cusp with mobile vegetations measuring $17 x 11 \mathrm{~mm}$. The abscess cavity communicates with left ventricular outflow tract (LVOT), with massive aortic insufficiency and the regurgitation jet filling $>75 \%$ of LVOT diameter (Figure 1). Ejection fraction was reduced to $45 \%$, with signs of right ventricle deterioration. Emergent surgery was indicated, patient was successfully operated. Biologic aortic valve was implanted (Edwards Inspiris Resilia A 23) with pericardial patch of the aortic root. Control TTE showed closure of pseudoaneurysm cavity and normal function of bioprosthetic valve. Patient recovered successfully and discharged home twelve days after surgery.
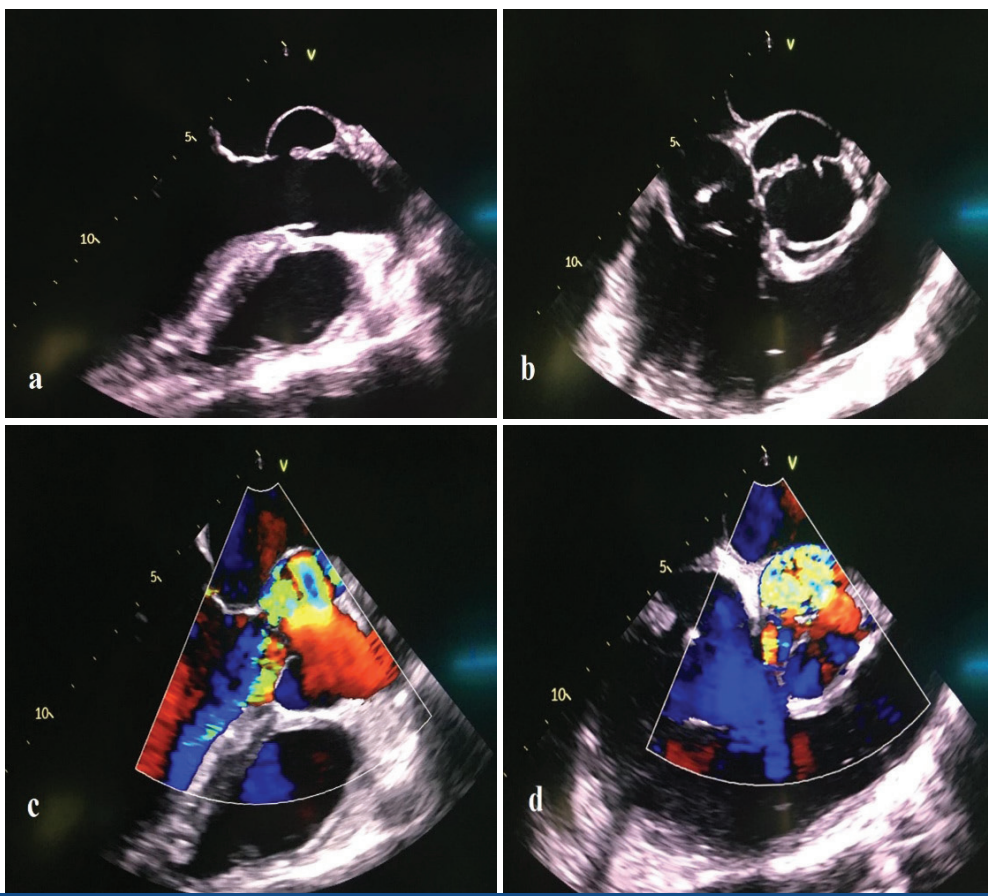

FIGURE 1. Intraoperative transoesophageal echocardiography showing: A, B) pseudoaneurysm cavity communicates with left ventricular outflow tract; C) massive aortic regurgitation; D) turbulent flow within the whole pseudoaneurysm cavity. 
63-year-old female patient, with multiple comorbidities, bilateral COVID-19 pneumonia and symptoms of acute heart failure. TTE showed massive vegetation on the anterior mitral leaflet measuring 15x15 mm, with peak pressure gradient on LVOT >120 mmHg, and highly susceptible aortic valve vegetation (Figure 2). She had to undergo urgent surgical operation. The mechanical mitral valve (On-X M 31) and mechanical aortic valve (On-X A 21) were successfully implanted. Postoperative recovery went well, and control TTE showed a good function of both mechanical valves.
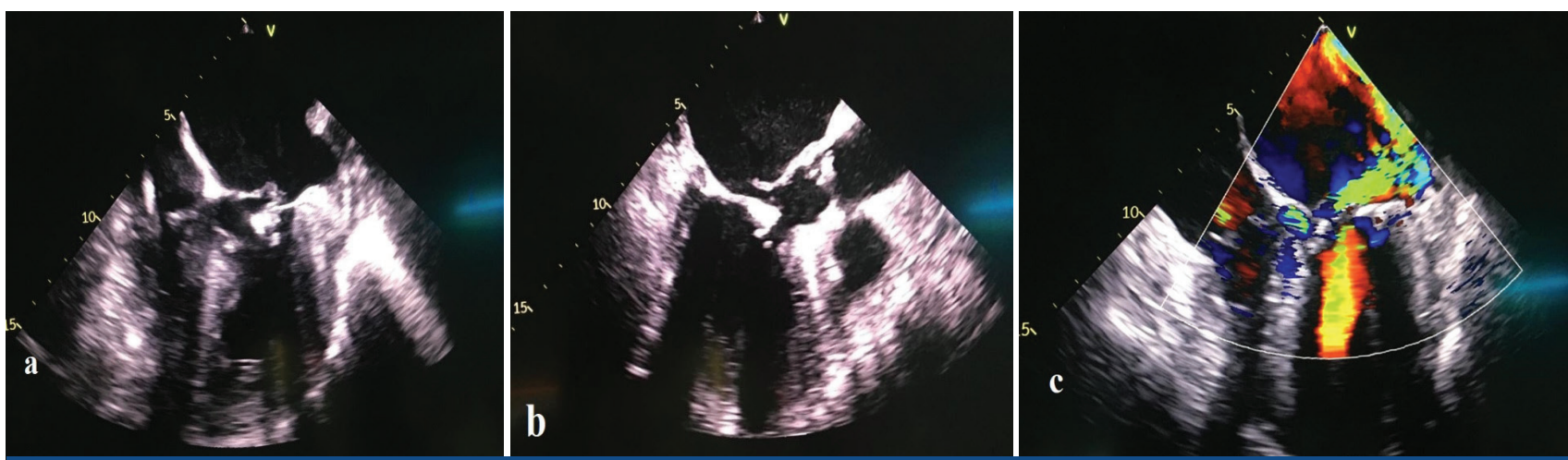

FIGURE 2. Intraoperative transesophageal echocardiography showing: A, B) vegetation on the anterior mitral leaflet, susceptible aortic valve vegetation; $\boldsymbol{C}$ ) massive mitral regurgitation.

Conclusion: Despite applied therapy, COVID-19 infection caused the hyperinflammation and suppresses our immune system to defend against pathogens, accelerating the symptoms which leads to cardiac collapse. Such clinical condition requiring urgent cardiac surgery, which could be performed only with the implementation of all epidemiological measures in the therefore planned COVID-19 hospitals.

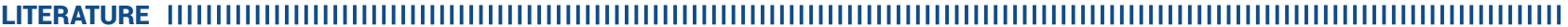

1. Escolà-Vergé L, Cuervo G, de Alarcón A, Sousa D, Barca LV, Fernández-Hidalgo N; IE COVID-19 investigators. Impact of the CovID-19 pandemic on the diagnosis, management and prognosis of infective endocarditis. Clin Microbiol Infect. 2020 Nov 28:S1198-743X(20)30718-7. https://doi.org/10.1161/01.cir.96.1.358

2. Habib G, Lancellotti P, Antunes MJ, Bongiorni MG, Casalta JP, Del Zotti F, et al; ESC Scientific Document Group. 2015 ESC Guidelines for the management of infective endocarditis: The Task Force for the Management of Infective Endocarditis of the European Society of Cardiology (ESC). Endorsed by: European Association for Cardio-Thoracic Surgery (EACTS), the European Association of Nuclear Medicine (EANM). Eur Heart J. 2015 Nov 21;36(44):3075-3128. https://doi.org/10.1093/eurheartj/ehv319

3. Kang DH, Kim YJ, Kim SH, Sun BJ, Kim DH, Yun SC, et al. Early surgery versus conventional treatment for infective endocarditis. N Engl J Med. 2012 Jun 28;366(26):2466-73. https://doi.org/10.1056/NEJMoa1112843

4. Chowdhury MA, Hossain N, Kashem MA, Shahid MA, Alam A. Immune response in CovID-19: A review. J Infect Public Health. 2020 Nov;13(11):1619-1629. https://doi.org/10.1016/j.jiph.2020.07.001 